\title{
Lessons from COVID-19 Pandemic: A Preliminary Analysis of Bangladesh's Responses
}

\author{
Rifat Mahmud \\ Assistant Professor, Department of Public Administration, University of Barishal, Barishal \\ 8200, Bangladesh, rifat.89@hotmail.com
}

\begin{abstract}
The first wave of the COVID- 19 disease has caused daunting and an unprecedented challenge for governments of the world. Decision-makers worldwide, including that of Bangladesh, had to initiate responses that were beyond the conventional measures. This paper offers the decision-makers in Bangladesh on the possible learning in the field of crisis management during this pandemic. The paper aims in focusing on the first phase of responses to COVID-19 (March-May) from the initial lockdown to the reopening of offices by the government of Bangladesh. Methodologically, the paper is a content analysis involving netnography approach of data collection from websites. The paper presents a finding of possible lessons of crisis responses in Bangladesh. The paper aims to create an agenda for learning lessons from the situation of the largest crisis to hit the world in centuries. The paper induces substantial value for policy-makers to be prepared for the second wave of the COVID- 19 crisis, to meet the challenges of the pandemic.
\end{abstract}

Keywords: Bangladesh, COVID-19, testing facility, expert committees, community participation

\section{Introduction}

Governments across the world are facing the severe challenge of responding to the threat of the COVID- 19 disease. All aspects of life such as health, education, economy, public security, and politics are critically being affected because of the current global health threat (Baniamin et al., 2020). The observations of measures to face the challenge of the pandemic highlight the responses of governments and their policies. Given the manifest possibility of the second wave of COVID- 19 is not farfetched (Xu \& Li, 2020) it is essential to reflect on what can be learned from a developing country like Bangladesh's responses to date.

COVID- 19 presents a fundamental challenge for the crisis management capacities of the modern state (Boin et al., 2020). The number of deaths in various countries due to the pandemic has placed huge strains on the health systems, and has had significant effects on the 
economic and social life of people of all classes. The first official report of the outbreak of the Coronavirus also known as Novel Coronavirus (SARS-CoV-2) was on 31 December 2019 in Wuhan, the capital of China's Hubei province. WHO declared this outbreak as a Public Health Emergency of International Concern on 30 January 2020 after it has spread globally, mostly affecting European countries such as Italy and Spain, with the worst-hit in the USA. As of 31 March 2021 there have been 128,540,982 confirmed cases of COVID-19, including 2,808,308 deaths worldwide. ${ }^{1}$ Bangladesh has 611,295 confirmed cases including 9,046 deaths till 31 March 2021 (ibid). Since the 1918 H1N1 influenza pandemic, the human race has not faced this scale of a pandemic.

When the outbreak of the pandemic took place the initial detection system did not work, or even many countries had no system as they did not take the problem seriously. Bangladesh confirmed its first case on 8 March when two non-resident Bangladeshis arrived from Italy, and the health minister admitted of the community level transmission in the mid of April. ${ }^{2}$ As the pandemic is now under initial control involving the 'new normal' featuring face masks, social distancing, and localized lockdowns, for most countries it took months to formulate policy interventions. This research does not offer a policy evaluation as to how Bangladesh may have mediated 'better' than other countries, but rather it points out the possible learning and insights in the field of crisis management. The paper focuses on the first phase of responses to COVID-19 (March-May) from the initial lockdown to the reopening of offices by the government of Bangladesh. The study also emphasizes two critical aspects or tasks that policy-makers face in a crisis: i) sense-making (understanding a crisis) and ii) making critical decisions and solving emerging problems.

In engaging with possible learning from managing COVID-19, the problems and the difficulties that policy-makers face when negotiating conditions of existential threat, a pervasive sense of urgency, and deep uncertainty (Rosenthal, et al., 1989; Boin et al., 2016), needs to be acknowledged. Public authorities initially knew little about the virus, its paths of transmission, and its health impact. Standard advice (World Health Organization Writing Group, 2006) involving how to manage pandemics was soon proven insufficient. Governments worldwide, including that of Bangladesh, were pressed into taking measures that, in the context of western liberal democracies, were seen as both unimaginable and infeasible (such as extensive lockdowns). As the measures were initiated, questions as to how to manage a lockdown, how to frame compensatory policy packages for struggling 
economies, and how to eventually 'loosen' these lockdowns became critical. Political leaders and policy-makers everywhere had to cope with this condition of deep uncertainty (Capano et al., 2020).

\section{Rationale of the study}

The study aims to help policy-makers enhance national crisis management structures and processes in the country. It is to be acknowledged that such probing into lessons will not help to produce policies that lead directly to prolonged reductions or elimination of reported infections. The lessons this study attempts can only have an indirect effect on fatality rates, economic trajectories, or long-term economic and societal impacts of the crisis in Bangladesh. The study discusses potential lessons for the essential crisis management tasks of sensemaking (understanding a crisis) and decision making. The study points out some cross-cutting factors that require further investigation to help us get prepared for the inevitable mega-crises of the second wave of COVID-19 that we will face soon.

\section{Methodological note}

This study mainly used 'netnography' to generate the data. Netnography is acknowledged as a useful research tool to analyze available online data (Heinonen \& Medberg, 2018). Netnography is conducted using two sources of data: news media and blogs, and social media (Lugosi et al., 2012; Kozinets, 2018). The rationale for choosing the method is the emerging nature of the data and the scarcity of data. For news media, this study follows established news platforms such as The Daily Star, United News of Bangladesh, The Business Standard, and Al Jazeera. This study followed other websites but not systematically.

\section{Findings and analysis}

\subsection{Making sense of the crisis: the challenge of uncertainty}

Policymakers of Bangladesh, including the Prime Minister, entered the COVID-19 pandemic in a mist of uncertainty. Uncertainty is a defining characteristic of a crisis (Rosenthal et al., 1989). In most crises, uncertainties are quickly reduced through established methods of information collection and analysis where crisis researchers refer to this process in terms of "sense-making" (Boin et al., 2020). However, the COVID-19 crisis was unique as it kept generating new uncertainties (for instance concerning transmissibility and symptoms)

Year 5/ 2021, Volume-5, Issue-2 | WWW.ispecjournal.org 
which kept policy-makers to be operating in a perplexing situation. This study identifies three (3) key factors that seemed to have played a limiting role in understanding COVID-19 for the policy-makers of Bangladesh.

The lack of testing capacity was one such critical factor for Bangladesh. Many countries did not have the laboratories or materials to ramp up testing and meet the WHO's "test test test" advocacy (Campbell \& Epstein, 2020). Countries that did begin testing soon and widely (Germany, South Korea) appear to have had a better idea of the extent to which the coronavirus had spread among their population (Hall \& Buck, 2020). Bangladesh, one of the most populous countries in the world with a density of 1104 persons per sq. km, experienced a quick spread of the virus. This requires large scale testing services to quickly identify who has the disease and arrange for them to receive the care needed. All districts in Bangladesh reported at least one COVID-19 cases but only 30 out of all 64 districts have testing facilities; thus, the regional disparity and scarcity of testing facilities are very much visible (Rahman et al., 2020). The laboratories designated for the tests are facing problems at every step from collecting samples to testing due to a shortage of adequate and skilled manpower and relevant logistics. ${ }^{3}$ With the second wave of virus eminent, the question of whether Bangladesh is prepared to test a sufficient amount of the population covering the whole country with the available resources and facilities in healthcare support services remains to be answered.

A second factor is the lack of ability to 'contact tracing'. Contact tracing is the process of identifying, assessing, and managing people who have been exposed to a disease to prevent onward transmission. ${ }^{4}$ The WHO prescribes that the recent contacts of each discovered patient are traced to identify and warn people that may have been endangered by the patient (World Health Organization Writing Group, 2006). Although this may not be seen as very difficult, it requires significant human resources (manual and health workers) to do it right and do it quickly. Some countries, like the Netherlands and the United Kingdom, simply gave up in the early phase of the crisis (Boin et al., 2020b). Other countries such as South Korea doubled down and made every effort to identify everybody at risk (Ryan et al., 2020). For contact tracing to be effective, countries need to have adequate capacity to test suspect cases promptly, which Bangladesh lacks. Bangladesh lacked in engaging communities about the disease, how to protect individuals and their communities, and how to suppress transmission. People outside the capital city, Dhaka, were very reluctant in maintaining the safety measures 
which led to community transmission by early April. Policy-makers, however, launched Corona Contract Tracing mobile app where only Bluetooth and location-based information is being used. But, the app is likely to be of much use as it doesn't tell anything about people who do not have the app installed. Since all mobile users in Bangladesh do not have smart-phone sets, a significantly large number of people may stay out of this listing, making the tracing less effective.

A third factor might be referred to as the humility of experts in the country. In many countries, decision-makers relied on experts (virologists, epidemiologists) to make sense of COVID-19 (Kupferschmidt, 2020). The Government of Bangladesh formed three (3) committees: i) National Committee; ii) Public Health Expert Committee and iii) National Technical Advisory Committee (NTAC) to tackle the COVID-19 situation in the country. However, the lack of coordination between the decision-makers (bureaucrats) and the committees was evident with the advice of committees being ignored by the decision-makers. ${ }^{5}$ The NTAC recommended that cattle markets should not be set-up in four (4) City Corporation areas (Dhaka, Naryanganj, Gazipur, and Chattrogram) on the occasion of Muslims secondbiggest religious festival, Eid-ul-Adha, and proposed to initiate digital marketplaces for sacrificial cattle trade. However, ignoring the Committee's recommendation all the City Corporation authorities allowed opening haats (markets). In May on the eve of Muslims' biggest religious festival, Eid-ul-Fitr, the NTAC recommended not to open the shopping malls. But, the Cabinet Division issued official order in opening up shopping malls on a limited scale, which led to the increase in the number of infected people after Eid, as predicted by the NTAC if shopping malls were opened (ibid).

The combination of these three factors points to the distinct challenges encountered in sense-making during COVID-19 by the various stakeholders in the country. Inferring from the crisis management literature, the study formulates a few lessons that may help to enhance sense-making capacity in the light of the imminent second wave of the virus.

I. Prepare to collect more rather than less data: Data collection in areas having a high level of infection in the first wave is essential for making sense of a crisis. Decision-makers have to learn how to ramp up data collection operations on short notice to cope up with the quality of medical services to prevent the spread of the virus.

Year 5/ 2021, Volume-5, Issue-2 | WwW.ispecjournal.org 
II. Speeding up the tracing procedure: Experts along with field-level bureaucrats should try to reach all segments of the society and requires an effective process to trace the infected people quickly in delivering medical faculties involving quarantining measures.

III. Coordination between expert committees and decision-makers: The decisionmakers require possessing actual information along with a sound assessment of the virus situation and expert committees need to provide feasible advice as per the information provided. The Cabinet Division along with field-level administration requires making necessary actions and arrangements in line with the advice given by the expert committees'.

\subsection{Initiating response or making the feasible decisions}

The Coronavirus turned out to be more contagious than initially thought. Infected people turned out to be asymptomatic, and the effects on a small, but not insignificant percentage of people were deadly (Boin et al., 2020b). Decision-makers had to face challenging health, social, and economic issues and had to initiate unprecedented policies of social distancing and impose quarantines. But the decision-makers were unaware whether most citizens and business owners would abide by the imposed regimes of social distancing. Governments soon encountered problems that threatened to undermine either feasibility of their response. Typical problems that required attention included the lack of Intensive Care (IC) beds, ventilators, and qualified personnel; a shortage of PPE; citizens stranded abroad; and the enormity of the looming economic damage (ibid). Bangladesh too lacked COVID dedicated hospitals especially outside the capital city, testing kits, labs, ventilators, and Personal Protective Equipments (PPE) (Rahaman et al., 2020). The hurdle that governments of various developing countries including that of Bangladesh faced was the apparent effectiveness and feasibility of existing plans in earlier crises as most countries had plans in place that had worked in response to SARS and H1N1.

The World Health Organization (WHO) urged for two (2) key non-pharmaceutical interventions (NPIs) to stopping the pandemic: social distancing and quarantining. The NPIs that countries are now accustomed to- social distancing, the use of face masks, the closing of social gathering points- were put into effect with limited scientific knowledge. There are contradictions among public health experts about the feasibility and effectiveness of the

Year 5/ 2021, Volume-5, Issue-2 | WWW.ispecjournal.org 
measures. According to one literature review, experts rejected non-pharmaceutical interventions including mask-use, school and workplace closures early in an epidemic and likely to be ineffective, infeasible, or unacceptable by the public (Aledort et al., 2007). A group of experts assembled by the WHO (World Health Organization Writing Group, 2006) agreed that forced isolation and quarantine are ineffective and impractical. On the other hand, scientific data and academic researchers have also found that through the social distancing model, the number of infected persons can be reduced significantly (Zhou, 2020; Milne \& Xie, 2020). For instance, Milne \& Xie (2020) in their research have found that the curve of infecting people dropped significantly where social distancing was applied. Bangladesh government initiated social distancing in late March arguing that this method can contain the outbreak of COVID-19. However, the feasibility of social distancing in a densely populated country Bangladesh was a matter of grave concern. Bangladesh with 170 million people, enforcing social distance has been next to impossible. ${ }^{6}$

The most consequential decision which governments across the world undertook was the imposition of lockdown. Most countries imposed some type of lockdown for an extended period. Countries such as the Netherlands, Germany, and Sweden were among the few countries that avoided complete lockdowns (Boin et al., 2020b; Pierre, 2020). To quell the spread of the pandemic, the Government of Bangladesh imposed area wise lockdowns throughout the country. Through the identification of infection clusters, lockdowns were implemented. The government declared a general holiday in the country from March 26 till May 30 to repress the infection. However, due to nationwide lockdown, low-income workers were deeply affected as they instantaneously have become jobless. The garment industries employ around 4.1 million workers, where all became jobless after the lockdown. ${ }^{7}$ The government of Bangladesh announced over $\$ 11$ billion stimulus package for different sectors including the agriculture and garments sector to provide soft bank loans and to assist people who have become economic victims of the pandemic. A total of 10.25 million people were brought under food assistance and cash cover in different categories. Although financial incentives were put into effect, its benefits are to be expected in long term. On the other hand, there was an immediate rise in unemployment due to a halt in economic activities. Incomes of the ultra-poor, moderately poor, and vulnerable non-poor in Bangladesh have fallen by $70 \%$ due to the pandemic (ibid, 2020). 
Although generalizing about the feasibility of different policies and initiations would be highly premature, this study formulates a few initial lessons concerning crisis management in Bangladesh for the coming second wave of the pandemic:

I. Need for a preparatory plan: Crisis plans rarely survive the first contact with reality (Clarke, 1999). The public acceptance of imposed lockdowns was low as expected, with law enforcement agencies found difficulty in implementing the lockdown. People panicked and there was a crisis of hand sanitizers, surgical masks, and liquid hand washes in the market. This observation suggests that preparatory plans such as keeping enough stocks of goods (medicines, foods, and non-pharmaceuticals) relevant to the pandemic should be taken as a starting point for the response, to be continuously challenged and adapted in the light of unfolding dynamics.

II. Strong political leadership: The crisis literature has often noted that politicians can fall prey to indecision or outright paralysis in the face of deep uncertainty and absent policy options. The public representatives were involved in the misappropriation of goods that were allocated for the poor who lost their jobs during the pandemic. The political leaders also had a minimal role to ensure that local citizens maintain the safety issues of social distancing. The political leaders are expected to be firmly in charge of an evidence-based repository of policy measures that must be available to them for the citizens.

\subsection{Rationale for better response capacities in the light of imminent second wave crisis of the pandemic}

The coronavirus crisis presented urgent challenges that decision-makers had to resolve under conditions of immense uncertainty: comprehending the nature of the virus, improvising social distancing and lockdown measures without evidence-based roadmaps, communicating with an apprehensive public, and maintaining economic and social well-being. This study does not offer a definite assessment of the crisis in Bangladesh, however, it appears that decisionmakers were not as effective as decision-makers of Germany, South Korea, and Singapore in crafting an initial response. The 'uncertain' character of COVID-19 caused additional challenges that made this crisis so much harder to manage than those crises that are more

Year 5/ 2021, Volume-5, Issue-2 | WWW.ispecjournal.org 
sharply delineated in time. New dilemmas arose, as exhausted policymakers kept discovering the limits of available expertise.

This study of the COVID-19 crisis unearthed a set of factors that shaped national policy responses, for better or worse. The paper ends with a list of factors that should be at the heart of future comparative research into the effectiveness and feasibility of national responses.

Preparation and planning: Most countries have experienced the pandemic and have detailed plans and protocols in place. The guidelines of the WHO inform these plans. The second wave would have a higher fatality rate which requires having substantial alternative strategies of interventions. There is a need for planning for the better implementation of nonpharmaceutical control measures along with health care capacities. To what extent the decision-makers are prepared for the unknown remains to be seen.

A cooperative relation with public health experts: Scholars have long studied the relationship between experts and policymakers (Fischer, 2009; Lodge \& Matus, 2014). A crisis forces policy-makers to hear from experts in suggesting policies and recommendations to counteract the spread of an epidemic (Rosenthal \& Hart, 1991). The COVID-19 crisis instigated the role of public health experts such as virologists and epidemiologists in the decision-making process. As discussed above, the government of Bangladesh formed three expert committees to tackle the COVID-19 outbreak. However, the role of these expert committees in the crisis decision-making process remained obscure. There has been evidence of a lack of coordination and cooperation among the bureaucrats, people's representatives, and expert committees. Decision-makers need to have a positive relationship with the committees. The committees must be equipped with information from the field level agencies and need to recommend feasible measures keeping in mind the social and economic necessities. There is a need of implementing those decisions prescribed by the committee and the decision-makers and the public health experts require the formulation of 'best technical solution' for the second wave of the pandemic.

Community participation for the local solution of local COVID-19 problems: Bangladesh has a good record of fighting disasters with community involvement. Successful community initiatives against natural disasters, such as cyclones and floods, have encouraged people to engage with one another; indeed civic participation is one of the strengths of the nation. As the COVID-19 in its first wave caused community transmission in a very quick 
time, thus community activism requires a substantial contribution to fighting the pandemic across the country. There is a need for a 'local COVID- 19 Protection and Control body' consisting of representatives of local government institutions, community health workers from the government, and representatives from local NGOs along with local influential members. The body would assist in identifying infected people with COVID-19, and arrange safe quarantine and proper diagnostic services, and inform urgently the community health workers, or health complex about any complex or alarming situation. Community health workers from the government and local NGOs, who have long experience of working with the community for promoting hygiene and health, can play a vital role as a referral as well as sample collection point with the government and other stakeholders, in working together with the community to fight the virus.

\section{Conclusion}

This study summarized different initial initiatives undertaken by the decision-makers of Bangladesh to tackle the spread of COVID- 19. This article formulated a few lessons that may help to enhance sense-making and decision-making capacity in the light of the imminent second wave of the virus. The factors identified in this article tend to generate critical aspects or tasks for the policy-makers for the crisis management of the pandemic.

\section{Declaration of Interest}

None

\section{Funding}

The author received no financial support for the research, authorship, and/or publication of this article.

\section{Notes}

1. WHO Coronavirus Disease (COVID- 19) Dashboard. Retrieved 14 October 2020, from https://covid19.who.int/

2. Community transmission on. Retrieved 14 October 2020, from https://www.thedailystar.net/frontpage/news/community-transmission-1892749 
3. Coronavirus: Kit shortage hampering testing. Retrieved 15 October 2020, from https://unb.com.bd/category/Special/coronavirus-kit-shortage-hampering-testing/53800

4. Contact tracing in the context of COVID-19. Retrieved 16 October 2020, from file:///C:/Users/user/Downloads/WHO-2019-nCoV-Contact_Tracing-2020.1-eng.pdf

5. Lack of coordination still prevalent in fight against COVID-19. Retrieved 25 October 2020, from https://tbsnews.net/coronavirus-chronicle/covid-19-bangladesh/lackcoordination-still-prevalent-fight-against-covid-19

6. Coronavirus: In dense Bangladesh, social distancing a tough task. Retrieved 27 October 2020, from https://www.aljazeera.com/news/2020/3/20/coronavirus-in-dense-bangladeshsocial-distancing-a-tough-task

7. Bangladesh: Poor struggle to survive amid COVID-19. Retrieved 27 October 2020, from https://www.aa.com.tr/en/asia-pacific/bangladesh-poor-struggle-to-survive-amid-covid $\underline{19 / 1819868}$

\section{References}

Aledort, J. E., Lurie, N., Wasserman, J., \& Bozzette, S. A. (2007). Non-pharmaceutical public health interventions for pandemic influenza: an evaluation of the evidence base. $B M C$ public health, 7(1), 208.

Baniamin, H. M., Rahman, M., \& Hasan, M. T. (2020). The COVID-19 pandemic: why are some countries coping more successfully than others?. Asia Pacific Journal of Public Administration, 42(3), 153-169.

Boin, A., Lodge, M., \& Luesink, M. (2020). Learning from the COVID-19 crisis: an initial analysis of national responses. Policy Design and Practice, 1-16.

Boin, A., Overdijk, W. I. E., Van der Ham, C., Hendriks, J., \& Sloof, D. (2020). COVID-19: Een Analyse Van de Nationale Crisisrespons.

Boin, A., Stern, E., \& Sundelius, B. (2016). The politics of crisis management: Public leadership under pressure. Cambridge University Press.

Campbell, S., \& Epstein, R. H. (2020). Why are coronavirus tests so difficult to produce? $B B C, \quad$ April.

Capano, G., Howlett, M., Jarvis, D. S., Ramesh, M., \& Goyal, N. (2020). Mobilizing policy (in) capacity to fight COVID-19: Understanding variations in state responses. Policy and Society, 39(3), 285-308. 
Clarke, L. (1999). Mission improbable: Using fantasy documents to tame disaster. University of Chicago Press.

Fischer, F. (2009). Democracy and expertise: Reorienting policy inquiry. Oxford University Press.

Group, W. H. O. W. (2006). Nonpharmaceutical interventions for pandemic influenza, national and community measures. Emerging infectious diseases, 12(1), 88.

Hall, B., \& Buck, T. (2020). Germany conducting more than 50,000 coronavirus tests a day. Financial Times website. https://www. ft. com/content/6a8d66a4-5862-49378d53- b2d10794e795. Published April, 2.

Heinonen, K., \& Medberg, G. (2018). Netnography as a tool for understanding customers: Implications for service research and practice. Journal of Services Marketing.

Kozinets, R. V. (2018). Netnography for management and business research. The SAGE Handbook of Qualitative Business and Management Research Methods, 384-397.

Kupferschmidt, K. (2020). How the pandemic made this virologist an unlikely cult figure. Science.

Lodge, M., \& Matus, K. (2014). Science, badgers, politics: Advocacy coalitions and policy change in bovine tuberculosis policy in B ritain. Policy Studies Journal, 42(3), 367390.

Lugosi, P., Janta, H., \& Watson, P. (2012). Investigative management and consumer research on the internet. International Journal of Contemporary Hospitality Management, 24(6), 838- 854 .

Milne, G. J., \& Xie, S. (2020). The effectiveness of social distancing in mitigating COVID-19 spread: a modelling analysis. medRxiv.

Pierre, J. (2020). Nudges against pandemics: Sweden's COVID-19 containment strategy in perspective. Policy and Society, 39(3), 478-493.

Rahaman, K. R., Mahmud, M., \& Mallick, B. (2020). Challenges of Testing COVID-19 Cases in Bangladesh. International Journal of Environmental Research and Public Health, 17(18), 6439.

Rosenthal, U., Charles, M. T., \& Hart, P. T. (Eds.). (1989). Coping with crises: The management of disasters, riots, and terrorism. Charles C Thomas Pub Limited. 


\section{ISSN 2717-7262 ISPEC Journal of Social Sciences \& Humanities}

Ryan, B. J., Coppola, D., Williams, J., \& Swienton, R. (2020). COVID-19 Contact tracing solutions for mass gatherings. Disaster Medicine and Public Health Preparedness, 1-

7.

Xu, S., \& Li, Y. (2020). Beware of the second wave of COVID-19. The Lancet, 395(10233), 1321-1322.

Zhao, P. J. (2020). A Social Network Model of the COVID-19 Pandemic. medRxiv. 